\begin{tabular}{|c|c|c|c|c|c|c|}
\hline \multirow{4}{*}{ Impact Factor: } & ISRA (India) & 3.117 & SIS (USA) & $=0.912$ & ICV (Poland) & $=6.630$ \\
\hline & ISI (Dubai, UAE & $=0.829$ & РИНЦ (Russia & $=0.156$ & PIF (India) & $=1.940$ \\
\hline & GIF (Australia) & $=0.564$ & ESJI (KZ) & $=5.015$ & IBI (India) & $=4.260$ \\
\hline & JIF & $=1.500$ & SJIF (Morocco & $=5.667$ & & \\
\hline
\end{tabular}

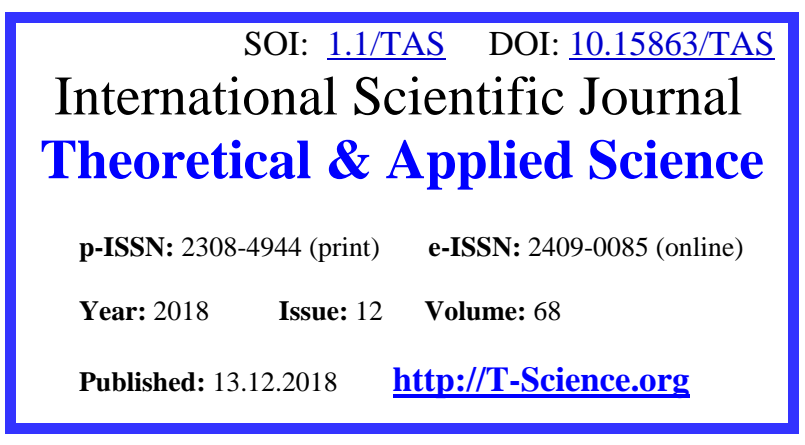

SECTION 31. Economic research, finance, innovation, risk management.

\section{International Scientific Journal}

p-ISSN: 2308-4944 (print)
QR - Issue

QR - Article
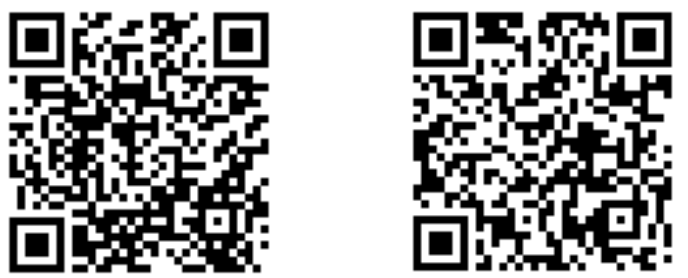

Sergei Rudolfovich Semenov

Candidate of economic science

Director of state enterprise

Information Marketing Centre «Aiylmaalymat» of Ministry of Agriculture of Food Industry and Land Reclamation of Kyrgyz Republic, Doctorate of Kyrgyz Economic University named after M. Ryskulbekov

\title{
PERSONALIZATION AND ACCESS TO STATE BODIES' INFORMATION IN THE SYSTEM OF INFORMATION INFRASTRUCTURE
}

\begin{abstract}
This article discusses the informatization in government e-services based on information systems, using the opportunity to provide the population with electronic data when requesting information and personalizing citizens in a single database. The ways of development of state information systems in the framework of the development of informatization in society, taking into account the development of digital information processes based on certain components of the overall integration, are shown. The main directions for the creation of electronic services in government bodies, through information interaction and infrastructure development when creating a modern information exchange system, have been identified.

Key words: Access to information, information society, personalization of data, information, government agencies, single portal, informatization, information systems.

Language: Russian

Citation: Semenov, S. R. (2018). Personalization and access to state bodies' information in the system of information infrastructure. ISJ Theoretical \& Applied Science, 12 (68), 53-56.

Soi: http://s-o-i.org/1.1/TAS-12-68-10 Doi: crossef https://dx.doi.org/10.15863/TAS.2018.12.68.10

\section{ПЕРСОНАЛИЗАЦИЯ И ДОСТУП К ИНФОРМАЦИИ ГОСУДАРСТВЕННЫХ ОРГАНОВ В СИСТЕМЕ ИНФОРМАЦИОННОЙ ИНФРАСТРУКТУРЫ}

Аннотация: В данной статье рассматривается информатизация в государственных органов электронных услуг на основе информационных систем, с применением возможности по предоставлению населению электронных данных при запросе информациии и персонализации граждан в единой базе. Показаны пути развития государственных информаџионных систем в рамках становления информатизации в обществе, с учетом развития цифровых информационных процессов основанных на определенных составляющих общей интеграции. Определены основные направления создания электронных услуг в государственных органах, путем информационного взаимодействия и развития инфраструктуры при создании современной системы обмена информации.

Ключевые слова: Доступ $к$ информации, информационное общество, персонализация данных, информация, государственные органы, единый портал, информатизация, информационные системы.

\section{Introduction}

C развитием информатизации свободный доступ к самой информации и информационным системам, как и к общим глобальным информационным структурам сегодня

имеет определенные проблемы, которые связанны с созданием и развитием самих государственных информационных систем, эти системы в своем развитии должны иметь юридические и технические стороны.
\end{abstract} неограничен. Доступ в разных странах населения к информации государственным структурам 


\begin{tabular}{|c|c|c|c|c|c|c|}
\hline \multirow{4}{*}{ Impact Factor: } & ISRA (India) & $=3.117$ & SIS (USA) & $=0.912$ & ICV (Poland) & $=6.630$ \\
\hline & ISI (Dubai, UAI & $=0.829$ & РИНЦ (Russia) & $=0.156$ & PIF (India) & $=1.940$ \\
\hline & GIF (Australia) & $=0.564$ & ESJI (KZ) & $=5.015$ & IBI (India) & $=4.260$ \\
\hline & JIF & $=1.500$ & SJIF (Morocco) & $=5.667$ & & \\
\hline
\end{tabular}

\section{Materials and Methods}

Сессия генеральной Ассамблеи Организации Объединенных Наций (ООН) 1946 года признала правом человека свободу на информацию. В 1984 году, в Совете Европы комитет министров отмечал, что «каждый человек в рамках юрисдикции государства-члена имеет право получать, запрашивать информацию в органах государственной власти». В 2004 году, в «Общей декларации ООН» право на информацию имело юридический статус, как «право доступа к информации государственных органов, которое должно реализовываться на национальном уровне с помощью исчерпывающего законодательства»[1]. Тем самым было положено начало формирования электронной услуги в глобальной информационной структуре предоставления информации на основе внедрения новых информационных технологий. На состоявшейся конференции «ЮНЕСКО между двумя этапами Всемирного саммита по информационному обществу» в 2005 году, рассматривалась деятельность государственных органов с их проблемами, где учитывалось развитие информационных технологий с их влиянием на гражданское общество Обсуждались возможности электронных услуг и их новые формы развития, которые участвуют в общественных процессах и затрагивают информационные вопросы информационного общества. Выступивший эксперт, профессор технологического университета У. Тэйлор, в своем докладе «Эволюция информационного общества и процессы электронного правления» говорил, что «концепция консолидированных услуг правительства» в виде электронного правления, еще не получила значительной поддержки во многих национальных государствах. Возникает определенная необходимость в совместных действиях государственных и коммерческих организаций, гражданского общества в решении данной проблемы [2].

Современное использование глобальной информационной инфраструктуры, сети интернета позволяет осуществлять в государственных органах планомерное внедрение электронных услуг, но внедрение этих информационных процессов и переход с бумажных на электронные носители требует определенного времени, правового, информационного взаимодействия и определенных финансовых средств. В правовом аспекте, в первоочередных задачах должен решаться вопрос об персонализации данных населения с учетом разработки законопроектов в сфере персонализации и защиты данных граждан. Персонализация данных предполагает сбор на законном уровне информации о близких, о наличии имущества (движимого, недвижимого), о номере мобильного телефона, о биометрических и других данных. Без создания такой информационной базы, невозможно создать базу учета информационных данных населения в электронном виде, которая должна составить основу всей информационной системы государственных органов по предоставлению электронных услуг. В мировой практике, направление о защите данных основывается на принятии в 1970 году (Германия) первого Закона «О защите персональных данных», направленного на регулировку обработки данных. Далее, в 1973-74 годах, приняты расширенные аналогичные законы в Швеции, США. В 1981 году, Советом Европы была ратифицирована «Европейская конвенцию о защите физических лиц при автоматизированной обработке персональных данных», определяющая защиту персональных данных. В 2001 году Российская Федерация подписала Конвенцию Совета Европы о защите персональных данных, это дало России в 2006 году разработать и подписать закон регулирующий обработку персональных данных. В мае 2018 года, в Европейском Союзе (EC) вступил новый закон General Data Protection Regulation (GDPR), направленный на усовершенствования к требованиям по защите персональных данных и укрепления прав субъектов [3]. По информации мировых агентств, в странах ЕС только за 2017 год кража персональных данных составила $65 \%$ от совокупного числа краж из организаций в мире [4]. Данный закон в правовом поле обеспечивает ответственность за несоблюдение правил хранения и обработки персональной информации, устанавливает мировые стандарты защиты данных, регламентирует межгосударственную передачу информации. Предписывает, что в странах ЕС иностранные, европейские компании имеющие большое количество персональных данных и оказывающие услуги электронной торговли, а также услуги в сфере банковских платежей, авиаперевозках и других элементах электронного взаимодействия, должны обеспечить прозрачность обработки данных и повысить их защищенность.

Двигаясь в международном правовом поле, Кыргызская Республика в 2008 году приняла Закон «Об информации персонального характера», в 2014 году Закон «О биометрической регистрации граждан Кыргызской Республики», данные законы являются юридическими документами определяющие обработку и защиту персональных данных населения страны [5]. В этих законах определяется порядок работы с данными, с 


\begin{tabular}{|c|c|c|c|c|c|c|}
\hline \multirow{4}{*}{ Impact Factor: } & ISRA (India) & $=3.117$ & SIS (USA) & $=0.912$ & ICV (Poland) & $=6.630$ \\
\hline & ISI (Dubai, UAE & $=0.829$ & РИНЦ (Russia) & $=0.156$ & PIF (India) & $=1.940$ \\
\hline & GIF (Australia) & $=0.564$ & ESJI (KZ) & $=5.015$ & IBI (India) & $=4.260$ \\
\hline & JIF & $=1.500$ & SJIF (Morocco) & $=5.667$ & & \\
\hline
\end{tabular}

учетом и своевременной регистрации граждан, выдачи идентификационных документов, а также качественное и своевременное предоставление населению этих услуг [6]. Принятые законы определяют пути развития и взаимодействия государства и населения в информационной сфере обмена данными и продвигают условия перехода к электронному правительству в стране, с учетом предоставления и оказания государственных услуг государственным структурам и гражданам. Принципы личного взаимодействия между государственными структурами и заявителем основанные на электронном взаимодействие и на электронном документообороте направлены на устранения коррупционных рисков. Соответственно, создание электронного правительства предполагает построение такой системы общественного управления, где общение граждан и бизнеса с правительством, общение между ветвями государственной власти, общение между государством и госслужащими будет связанно с управлением документами, электронным документооборотом[7]. Можно отметить, что сегодня органы государственной власти для повышения прозрачности своей деятельности, еще не в полной мере используют возможности информационного общения. Из-за слабого финансирования или его отсутствия такового наблюдается недостаток квалифицированных государственных кадров. Направление по подготовки квалифицированных специалистов и создание соответствующих программ по внедрению информационных систем в государственных структурах, с организацией процедур объединяющих эти направления развития информационного взаимодействия в единую информационную инфраструктуру, будут способствовать обеспечению максимальной продуктивности государственных электронных услуг. Информационная инфраструктура должна характеризоваться как гармоничная система средств передачи данных, действующих в системе юридических, организационноэкономических и технических условий, обеспечивающих эффективное взаимодействие между субъектами информационного рынка [8], соответственно данное развитие будет направленно и на повышении уровня жизни населения.

\section{Conclusion}

Создание в разных странах единых порталов государственных и услуг, в том числе и в странах Евразийского экономического союза определяет движение в сторону «электронного правительства», тем самым обеспечивает доступ населения к государственным услугам и интересующим сведениям. В Кыргызстане, запущен портал государственных услуг и сведения о государственных услугах - www. gosuslugi.tazakoom.kg, на данное время предлагаются электронные услуги двадцати двумя министерствами и государственными органами [9], на сегодня в стране действует «Единый реестр государственных услуг» включающий 373 услуги, из них: 149 бесплатные, 224 платные [10]. Единый портал государственных услуг доступен пользователям сети интернет и способен обеспечить поиск нужный гражданам информации по государственным услугам. Доступ населения к государственным информационным системам осуществляется с помощью цифрового удостоверения гражданина Кыргызской Республики нового образца, с наличием электронного чипа. Данная система обеспечивает единый универсальный, контролируемый доступ населения к приложениям и данным информационной системы, обеспечивая безопасность и сохранение данных. Дальнейшее развития информационной инфраструктуры государственных услуг, получило в объединении информационных систем государственных органов в единую межведомственную информационную структуру с созданием общей информационной системы «Тундук» - www.tunduk.gov.kg. По прогнозам специалистов внедрение информационной системы «Тундук» сэкономит до 300 миллионов долларов в год бюджету страны. На сегодня к системе произвели подключения 36 государственных органов и она работает в тестовом режиме. Разработка и полноценный запуск информационной системы «Тундук» будет способствовать созданию общей государственной информационной инфраструктуры с единой точкой доступа к информации, где данная система должна связать цифровое взаимодействие государственных органов в единый комплекс государственного управления информационными ресурсами. 


\begin{tabular}{lllllll} 
& ISRA (India) & $=\mathbf{3 . 1 1 7}$ & SIS (USA) & $=\mathbf{0 . 9 1 2}$ & ICV (Poland) & $\mathbf{= 6 . 6 3 0}$ \\
Impact Factor: & ISI (Dubai, UAE) $=\mathbf{0 . 8 2 9}$ & PUHL (Russia) $=\mathbf{0 . 1 5 6}$ & PIF (India) & $=\mathbf{1 . 9 4 0}$ \\
& GIF (Australia) & $=\mathbf{0 . 5 6 4}$ & ESJI (KZ) & $\mathbf{5 . 0 1 5}$ & IBI (India) & $\mathbf{= 4 . 2 6 0}$ \\
& JIF & $\mathbf{1 . 5 0 0}$ & SJIF (Morocco) $=\mathbf{5 . 6 6 7}$ & & \\
\hline
\end{tabular}

\section{References:}

1. Mendel, T. (2008). Information freedom. Comparative legal researching. (p.9-11). Paris: UNESCO.

2. (2005). UNESCO between two stage of Global Summit on information society. materials of international conference (Saint-Petersburg, Russia, 17-19.05.2005). (p.608). M.: IRIO.

3. (2018). Law of European Union «Common rules of data security», General Data Protection Regulation (GDPR). Retrieved December 01, 2018, from https://gdpr-info.eu/

4. (2018). Analytics data of international company InfoWatch, in sphere of information security to external and internal threats. Retrieved December 01, 2018, from https://www.infowatch.ru/analytics/leaks monit oring

5. (2018). Ministry of justice of Kyrgyz Republic, Law of «Personal information». Retrieved December 01, 2018, from http://cbd.minjust.gov.kg/act/view/ru-ru/202269

6. (2018). Ministry of justice of Kyrgyz Republic, Law of «Biometrical registration of citizens of Kyrgyz Republic». Retrieved December 01,
2018, from http://cbd.minjust.gov.kg/act/view/ru-ru/205357

7. (2018). Electronic government. Retrieved December 01, 2018, from https://allforjoomla.ru/info/308-jelektronnoepravitelstvo

8. Simonov, S. G., \& Klepikova, A. M. (2009). Development of market of information services like necessary condition to formation of Russian economics information model. Industrialinnovative development at the present stage: state and prospects. (pp.55-61). Pavlodar, InEU.

9. (2018). Single portal of electronic government services of the Kyrgyz Republic. Retrieved December 01, 2018, from https://gosuslugi.tazakoom.kg/catalog

10. (2018). Ministry of Justice of the Kyrgyz Republic, Resolution of the Government of the Kyrgyz Republic of March 14, 2018 No. 134 "On approval of the Temporary rules for use of the State portal of electronic services» Retrieved December 28, 2018, from http://cbd.minjust.gov.kg/act/view/ru-ru/11749 